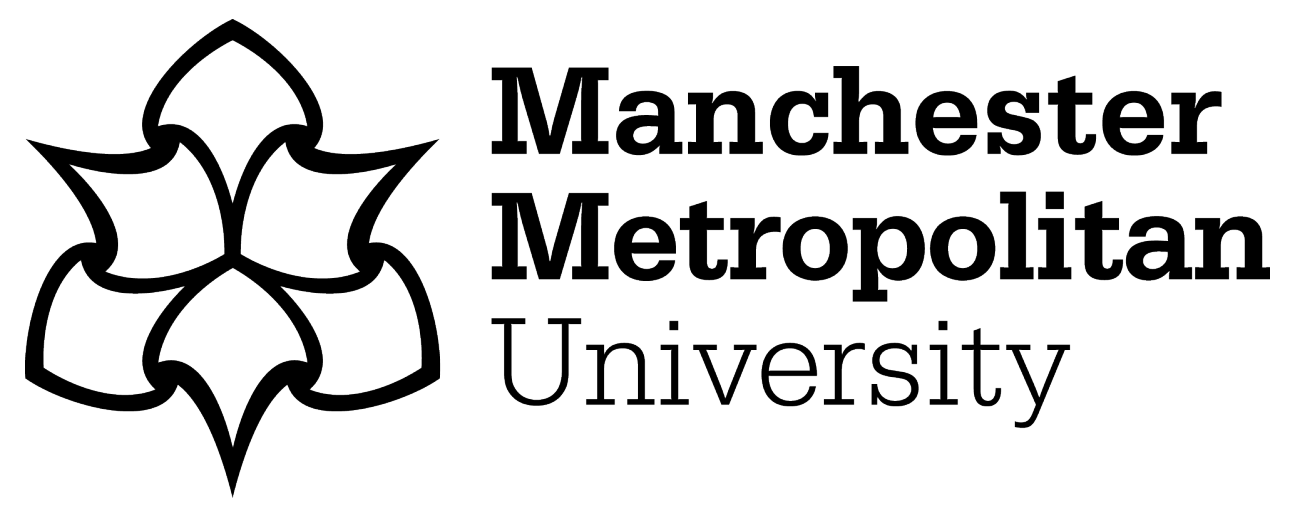

Chaplin, R and Davidson, I (2016) What are the experiences of people with dementia in employment? Dementia (London), 15 (2). pp. 147-161. ISSN 1741-2684

Downloaded from: https://e-space.mmu.ac.uk/620228/

DOI: https://doi.org/10.1177/1471301213519252

Please cite the published version 


\title{
What are the experiences of people with dementia in employment?
}

\author{
${ }^{1}$ Ruth Chaplin and ${ }^{2}$ lan Davidson \\ ${ }^{1}$ Occupational Therapist, Older Adult Mental Health Services, The Meadows, UK \\ ${ }^{2}$ Senior Lecturer in Physiotherapy, Manchester Metropolitan University, Manchester, UK
}

\section{Abstract}

Statistics show that an increase in the statutory retirement age in the UK will mean that many more people will develop a dementia while still in employment. A review of the literature confirmed that there are no existing studies in the UK which examine this issue in any detail. The aim of this study was to investigate the experiences of people who develop a dementia while still in employment and to understand how they make sense of these experiences: therefore a qualitative explorative inquiry based on an Interpretive Phenomenological Analysis methodology was used. Interviews with five people who had developed a dementia while still in employment were carried out, with ages ranging from 58 to 74 years. Interview transcripts were analysed and four super-ordinate themes were identified: the realization that something is wrong: managing the situation in the workplace: trying to make sense of change: and coming to terms with retirement or unemployment. The results showed that people who develop a dementia while still in employment do not always receive the 'reasonable adjustments' in the workplace to which they are entitled under the Equality Act (2010). Some of the participants felt that they were poorly treated by their workplace and described some distressing experiences. The study highlights the need for more effective specialized advice and support regarding employment issues and more research into the numbers of people in the UK that are affected by this issue.

\section{Keywords}

dementia, early onset, employment, work, occupation, subjective experiences 


\section{Introduction}

The Alzheimer's Society (2010) estimate that there are approximately 650,000 people in the UK living with a diagnosis of dementia. This number is probably an under-estimation as many more who have the condition will remain undiagnosed. Around 17,000 people under the age of 65 have a dementia, but it is not known how many of these were still in employment when signs and symptoms of the condition developed.

There are an estimated 1.4 million people still in employment over the age of 65 in the UK (Office of National Statistics, 2012) and, with the removal of the statutory retirement age in 2012, this number has begun to rise. It is estimated that if the retirement age goes up to 70 , the number of people still in employment who develop a dementia will rise threefold to an estimated 54,674 (Brechin, 2004) or $8.5 \%$ of the total prevalence of dementia in the UK.

Literature considering a diagnosis of dementia for those of working age has focussed on the social and economic consequences of the loss of the work role for the person with dementia and their family. This could be the loss of the provider role and financial difficulties (Harris \& Keady, 2004: Luscombe, Brodaty, \& Freeth, 1998: Tindall \& Manthorpe, 1997): the loss of the worker role and consequent changes in their sense of identity and self worth (De Baggio, 2002: Harris \& Keady, 2004: Lee, 2003: McGowin, 1993). In addition, changes in levels of social contact and a loss of meaningful occupation due to leaving employment have also been noted (Armstrong, 2003: Beattie, Daker-White, Gilliard, \& Means, 2002: Roach \& Keady, 2008).

Some positive aspects of leaving work such as the sense of relief (Lee, 2003: Mckillop, 2005: Ohman, Nygard, \& Borell, 2001) and a sense of renewed purpose through telling their story of living with dementia (Davis, 1989: De Baggio, 2002: Lee, 2003) have also been reported. Only one existing study, carried out in Sweden, interviewed people with dementia or cognitive impairment while still in employment (Ohman et al., 2001). They found that some people wanted to stay in employment with adjustments, while others wished to leave and refocus their lives. They concluded that participants were generally well supported in their decisions by their workplace colleagues, managers and the private healthcare system.

The purpose of this present study was to focus specifically on the experiences of people developing a dementia while still in employment in the UK. As the emphasis of this study is on how the participants make sense of what is happening to them, a qualitative exploratory study based on Interpretive Phenomenological Analysis (IPA) (Smith, Flowers, \& Larkin, 2009) was thought to be an appropriate approach to use in gathering and analysing the data.

\section{Participants}

All participants had an ICD-10 diagnosis of Alzheimer's disease or vascular dementia and were patients attending a Community Mental Health Team or Memory Assessment Service in the North of England. Information about the research project was given to all staff working in these teams and they discussed the project with any patients they had 
who met the inclusion criteria. Five patients gave permission for the researcher to contact them and all of these five patients agreed to take part.

To be eligible for inclusion in the study patients needed to be:

- Diagnosed with a dementia and under the care of a Consultant Psychiatrist.

- Currently in employment or having left employment in the last 12 months.

- Able to give informed consent to take part.

Throughout the paper the participants are referred to by their work roles, rather than by a number or pseudonym. This decision is informed by the observation that their work roles are integral in their stories and it was felt to help the narrative of each individual experience.

Ethical approval was gained from a North West of England Ethics committee (Reference no 12/NW/0020) and the relevant Research and Development NHS Trust Department in the area the research took place.

\section{Procedure}

Participants were individually interviewed on a single occasion in their own home. The interviews lasted for between $40 \mathrm{~min}$ and $80 \mathrm{~min}$. Each interview was audiotaped to allow for transcribing. Participants were invited to have a friend or family member present if they wished. A semi-structured interview schedule was used. It consisted of open ended questions to allow the participant to recount their experiences of developing a dementia while still in the workplace. Prompts were used during the interview if needed. The main areas of exploration of the interview are shown in Box 1.

\section{Data analysis}

The interviews were analysed using IPA (Smith et al., 1999). The aim of this was to identify any common themes in the data. Interviews were first analysed individually through a process of reading and re-reading many times to facilitate immersion in the individual experience. Margin notes were then grouped into themes which were then grouped into over-arching, super-ordinate themes. Once each interview had been analysed in this way, a group level analysis commenced where themes and sub-themes from individual analysis were drawn together and grouped with similar themes from other interviews so that new themes and sub-themes were formulated.

To ensure rigour and to guard against possible sources of researcher bias, the transcripts with their thematic analysis were given to a colleague who was experienced in this technique of analysis but who was not working in the field of dementia. She followed the categorization of themes through to the final formulation of super-ordinate themes and was in agreement that they reflected the words of the participants. In addition, though member checking is not used in IPA, the participants were given a summary of the study's main findings to see if they felt it reflected their experiences. 
What were the first signs and symptoms of dementia that the participants were aware of in the workplace and how did they and their colleagues react?

Did they use and particular strategies or techniques to manage impairments in the workplace?

Were they offered reasonable adjustments to their role and what was the outcome of their employment? If they have left employment, how have they and their family adapted to life without work?

\section{Results}

Five people were identified as meeting the inclusion criteria for the study and all agreed to take part. There were four men and one woman, aged between 58 and 74 years. Three had left employment: two classed themselves as semi-retired. A summary of participants is given in Table 1.

The results demonstrated four super-ordinate themes which are summarized in Table 2.

\section{The realization that something is wrong}

The first super-ordinate theme describes how participants first become aware that they are having difficulty in some areas of functioning in the work place.

\section{An awareness of changes in their functioning in the work place}

The first signs of cognitive impairment varied between the five participants. For the Nursing Assistant it was a visuo-spatial impairment which meant that he struggled to write in the correct places in patient's notes.

For three participants, the Engineer, the Businessman and the Schools Meals Assistant, the first signs were poor short-term memory and a difficulty in remembering names and adjusting to new tasks.

The School Meals Assistant described how:

They went on computers and I found I couldn't keep up with it, I got all mithered, everything seemed confused to me and I couldn't understand why.

Table 1. Summary of participants.

\begin{tabular}{|c|c|c|c|l|l|}
\hline $\begin{array}{c}\text { Participant } \\
\text { no }\end{array}$ & Occupation & Diagnosis & $\begin{array}{c}\text { Age } \\
\text { (gender) }\end{array}$ & $\begin{array}{l}\text { Current } \\
\text { employment status }\end{array}$ & $\begin{array}{l}\text { MMini } \\
\text { mental } \\
\text { state exam } \\
\text { score) }\end{array}$ \\
\hline 1 & $\begin{array}{c}\text { Nursing } \\
\text { Assistant }\end{array}$ & $\begin{array}{c}\text { Alzheimer's disease. } \\
\text { Diagnosed July 2011. }\end{array}$ & 60 (male) & $\begin{array}{l}\text { Early retirement on } \\
\text { grounds of ill } \\
\text { health, July 2011 }\end{array}$ & $25 / 30$ \\
\hline
\end{tabular}




\begin{tabular}{|c|c|c|c|l|c|}
\hline 2 & $\begin{array}{c}\text { Heavy goods } \\
\text { vehicle driver } \\
\text { (HGV } \\
\text { Driver) }\end{array}$ & $\begin{array}{c}\text { Vascular dementia. } \\
\text { Diagnosed March } \\
2011 .\end{array}$ & 60 (male) & $\begin{array}{l}\text { Dismissed Feb' 2012 } \\
\text { claiming } \\
\text { employment } \\
\text { support allowance. }\end{array}$ & $28 / 30$ \\
\hline 3 & $\begin{array}{c}\text { School Meals } \\
\text { Assistant }\end{array}$ & $\begin{array}{c}\text { Alzheimer's disease. } \\
\text { Diagnosed June 2011 }\end{array}$ & 58 (female) & $\begin{array}{l}\text { Dismissed Feb' 2012 } \\
\text { claiming } \\
\text { employment } \\
\text { Support allowance }\end{array}$ & $26 / 30$ \\
\hline 4 & $\begin{array}{c}\text { Owner of his } \\
\text { family } \\
\text { business. }\end{array}$ & $\begin{array}{c}\text { Alzheimer's disease. } \\
\text { Diagnosed Nov' 2011 }\end{array}$ & 71 (male) & $\begin{array}{l}\text { Self-employed. } \\
\text { Semiretired from 08/11 }\end{array}$ & $27 / 30$ \\
\hline 5 & $\begin{array}{c}\text { Engineer/ } \\
\text { lecturer }\end{array}$ & $\begin{array}{c}\text { Alzheimer's disease. } \\
\text { Diagnosed Dec' 2011. }\end{array}$ & 74 (male) & Self-employed. \\
Semiretired. & \\
\hline
\end{tabular}

For the HGV Driver the first and only difficulty he was aware of was a word-finding problem:

It was one particular place really that I could never remember the name of even though I was there, I spent six hours getting there but I couldn't remember the name of it....

\section{A reluctance to acknowledge the signs}

All of the participants described how they did not initially think that these difficulties in specific areas of functioning were the first signs of something more serious. At this stage, they tended to ascribe the changes to pressure of work, new work roles, life-long traits, such as poor memory or declining physical skills such as poor eyesight.

The Businessman, for whom English is a second language, described how his firm had been through a big expansion over the last few years and that he thought that this had contributed to his poor health:

It was very interesting to see, unfortunately I overlooked one item, I wasn't anymore 25 , consequently it had a very detrimental effect on my health, it came to breakdown.

The participant who was a Nursing Assistant initially put his visuo-spatial problems down to poor eyesight but then noticed other changes:

All through my life I had been a good speller and I even got to the point one day that I spelled my own name wrong and at that point I did become concerned. 
Table 2. Summary of group themes - super-ordinate themes.

The realization that something is wrong

An awareness of changes in functioning in the workplace

A reluctance to acknowledge the signs

Sharing the fears

Managing the situation in the workplace

Self-management

Feeling under scrutiny

A lack of consultation about management decisions

Trying to make sense of the changing situation

A belief in continued competence despite the realization of impairment

Feeling abandoned by the workplace

Feelings of resentment towards the workplace

Acceptance of the final outcome

Coming to terms with retirement or unemployment

Reflections on the meaning of work in their lives

Difficulty in obtaining advice and information

Adjusting relationships and roles with friends and family

Finding new activities

A positive outlook for the future

\section{Sharing the fears}

They then began to suspect it was something more serious and all discussed their difficulties with their partners and were encouraged to seek further help.

The School Meals Assistant confided in her partner about the difficulties she was having in using the new computer system:

He thought it was just the computers that I'd not been used to and put it down to that but then I could tell, I wasn't feeling right.

The Businessman described how he had tried to dismiss his wife's concerns and how:

One day she lost her patience and consequently she wanted a little bit more...you must remember this you must remember that you asked me three times and slowly sinks in something is wrong.

At this stage, only one of the participants openly discussed their difficulties with their manager, the rest preferring to try to manage their difficulties themselves.

The Nursing Assistant went to the Sister on his ward:

I did at one point realise that I had put a gentleman's pyjama top on inside out and that to me was a siren to say this is not good enough and very quickly after that, after talking to the Ward Sister, we went together to Occupational Health. 


\section{Managing the situation in the workplace}

The second super-ordinate theme to emerge was the ways in which the participants managed their impairments in the workplace and how their workplace managers and colleagues responded.

\section{Self-management}

Three of the participants were able to discuss strategies for managing the symptoms of their illness in the workplace. They all spent more time and effort in planning and organising tasks and acknowledged how difficult it could be even with these strategies in place.

The Nursing Assistant would spend more time preparing his trolley for patient care duties:

... when I was going to a patient I knew who I was going to, what I was going to do and had everything set up not to leave that patient again until that work was complete.

For the Businessman, his wife, who is also a part owner of the company, started to come into work more to assist him in the tasks he was struggling with:

It was quite convenient for me that Sylvia has an excellent memory, birthdays anything like that and when we went to meetings she would whisper the name of the person particularly if it is someone who is a client of the company.

He would also spend more time planning for meetings.

The Engineer said:

Well I write it down, use my diary and I have files of things, I don't remember what I've got so I keep looking through things but I get there in the end.

\section{Feeling under scrutiny}

The three participants who worked more closely with others described how their managers or colleagues had noticed that they were having difficulties in some tasks. They mainly tried to manage this by increased observation of the employee but did not discuss this with the employee. Consequently, the participants felt that they were being watched covertly and they would have preferred to have been consulted about this. The Nursing Assistant described how he was taken off 'main duties' on the ward such as supervising medication, putting in cannulas and writing in notes and was assigned to work in a pair with another nursing assistant. While he agreed that this was a reasonable adjustment to make to his duties, the way in which it was covertly done had a negative effect on his performance.

What Sister had actually done was to get one or two people to observe me when I didn't know. Well let's put it this way, I did know I was being observed some of the time and I did become apprehensive when I knew people were watching me.

For the School Meals Assistant who could not use the new computer system, another member of staff was put by her side to do that part of the job for her. She was aware of some resentment from colleagues who she thought put it down to her being lazy:

Some of them was funny at first but I think it was because they didn't think I was pulling my weight, which I was, I just wasn't doing it right. 
She would have preferred for the reasons for this assistance to be discussed openly with her and her colleagues so that they knew that her difficulties were genuine.

In the case of the Businessman, though he did not have a management structure above him to scrutinize his abilities, he was very aware that his son was moving to take more control of the business and that he needed this help:

I felt I had no choice, any decision I felt I was going to make, and the chances of them being wrong decisions well in my opinion up to $70 \%$ if not $80 \%$.

\section{A lack of consultation about management decisions}

Though two of the participants were given some adjusted duties when their employers became aware that they were having difficulties, none of the participants said that they were offered any 'reasonable adjustments' to their work role under the Equality Act (2010) after diagnosis. None of the participants were referred to a Disability Employment Advisor by their workplace.

The HGV Driver and the School Meals Assistant were advised to take sickness leave when their employers became aware of the extent of their difficulties at work. They were advised to seek further assessment of their difficulties from their GP. Both of their GP's did make referrals on, one to a Neurologist and one to a Psychiatrist.

Both these participants were then on sickness leave for the full six months and never returned to work.

The Nursing Assistant stayed in work with slightly adjusted duties until he was given his diagnosis a few weeks later by a Neurologist. He was then summoned to a meeting with Occupational Health and his Ward Sister. This meeting was held on the ward he worked on and his employment was terminated at once:

I feel the situation was taken behind closed doors and I don't believe that there were people around those closed doors, it was a case of yes he's got it and we're not prepared to even look for anything.

\section{Trying to make sense of the changing situation}

All of the participants struggled to make sense of how quickly their work situation was changing at this stage and some believed there was still a work role that they could achieve.

\section{A belief in continued competence despite the realization of impairment}

Three of the participants felt that they would have been able to carry on with an adjusted work role when they were diagnosed with dementia, while the School meals Assistant and the Businessman believed that they were no longer competent. 
For the Nursing Assistant, though he was able to acknowledge that he had some difficulties in direct nursing tasks with patients, he felt that he retained many valuable skills on the ward.

I ended up as being a well-known person at being able to get someone down from that level of wanting to punch you to sitting down for a cup of tea. I could still do that.

The HGV Driver continued to feel that he was a competent driver and there was no evidence that his word-finding problem affected his ability to drive. He was frustrated by the fact that his employers had asked Driver and Vehicle Licensing Agency (DVLA) to remove his licence without giving him the opportunity to have a Driving Safety Test at his Regional Driving Centre.

I'd love to drive to get my HGV back, I know I can still drive 'cos I feel like something like that, I've been doing it for 36 years it's instilled into you.

The Engineer described how he did his first lecture after the onset of his illness:

The lecture was about the tsunami and in terms of what is going on with me now, the interesting thing was many of my slides were pictures, there were no words on it, the words had to come from here and I had absolutely no problems at all.

\section{Feeling abandoned by the workplace and consequent feelings of resentment towards the workplace}

Three of the participants expressed feelings of abandonment in how their employment situation was managed by their workplace. They felt that when they received their diagnosis and informed their workplace, no real attempt was made to find any adjusted work role for them. None of the participants was a member of a Trade Union and they did not have any formal representation at their meetings with Human Resource Departments.

The two participants who went onto sickness leave for six months both said that they were rarely contacted by their work place or Human Resources and they were not warned when their sickness pay was ending. Both experienced financial hardship when this happened.

The School Meals Assistant said:

I did think they were trying to get rid of me, no one called me.

\section{The HGV Driver said:}

I had to keep phoning them...they just forgot me I phoned them up at one stage and they didn't know who I was.

In addition, none of them was given the opportunity to go back to the workplace to say goodbye to their colleagues when there employment was eventually terminated and they expressed regret about this.

They all felt that there was no real will in the workplace to find a more suitable role or acknowledge their remaining skills. When the Nursing Assistant asked about other jobs 
in his workplace he was told that they did not have insurance for him now that he had a diagnosis of Alzheimer's disease, which is an incorrect statement:

...Occupational Health said no one would give me insurance so at that point I thought well there's no point in trying to work myself into something when no one would be able to employ me.

The two participants who went on extended sickness leave were not invited to meet with Human Resources until they had been away from work for a year and they felt this meeting was a formality and not a real opportunity to address their needs. Both were formally dismissed on grounds of incompetence.

The HGV Driver said:

They said there were no jobs I could do, safety wise, in the depot, the will wasn't there really was it?

\section{An acceptance of the final outcome}

Four of the participants expressed an acceptance of the final outcome of their employment.

\section{The HGV Driver said:}

I was quite happy with the outcome, for my health, but it was a bit long, 12 months, I think it should have been sooner but never mind.

The Businessman now keeps a financial interest in the company along with his wife and son and is consulted about major decisions.

The Engineer still lectures and organizes conferences with the assistance of international colleagues:

That sort of activity will continue until I'm told I have to retire or they find someone else, well I hope they do, I can't go on indefinitely.

\section{Coming to terms with retirement or unemployment}

Two of the participants are now on Employment Support Allowance, one has taken early retirement and two classed themselves as semi-retired.

\section{Reflections on the meaning of work in their lives}

Four of the participants said that their work was a big part of their life and that they had enjoyed it and taken a pride in doing it well. Two participants, the Businessman and the Engineer had chosen to work beyond retirement age because they loved their work so much. The Businessman said:

Work was my $80 \%$ hobby, you have a hobby on the golf course and I have my work. 


\section{Effects on their relationships with others}

All of the participants said that leaving work had affected their family and their relationships. The Nursing Assistant and the HGV Driver both had partners who are still working and they had taken on more domestic roles to help them. For the HGV Driver and the School Meals Assistant, leaving work had meant some financial hardship and consequent worry.

\section{The HGV Driver said:}

We always had plenty of money, ...then suddenly we had no money and you start thinking about the future. We've still got a mortgage and I worry about that.

\section{A positive outlook for the future}

Despite their difficult experiences all of the participants were determined to be positive about their future.

The Businessman said:

My wife is happy, I am at home more. We live a settled life now, go visiting people.

All of the participants said that they had taken up new hobbies or restarted old ones since leaving or reducing their work. The three participants who are under the age of 65 had been referred to the Young Onset Dementia Service in their local area and had become involved in the various social and leisure activities facilitated by this service.

The School Meals Assistant said:

I'm probably happier now because I do different things, there's no day when I don't do anything even if I just go to town and I go to the gym and do stuff with Kath (Young Onset Dementia Worker).

The Nursing Assistant said:

Well I've put my name down to do as much as I can because after being in work all my life just being stuck at home is not good enough for me, I need to do something, I'm not going to be sat down here and be moaning because my wife's working shifts and my sons are all out working, I want to be doing something everyday

The Engineer was still planning future conferences:

One of the things I assume and still do assume is that I can do everything

\section{Discussion}

As in Ohman et al.'s (2001) study of people with a cognitive impairment in the workplace, the participants in this present study all experienced slightly different first signs and symptoms of dementia and these tended to be most noticeable in their work environment. The realization that something is wrong (seen in the first super-ordinate theme) precipitated a tendency at this early stage to ascribe these changes to other things going on in the participant's lives, such as changes in work role or pressure of 
work or to physical health problems. However, the underlying feeling in three of the interviews is a growing fear that something more serious is going on. This awareness of the illness at a relatively early stage has been discussed in autobiographical accounts of several people of working age with a diagnosis of Alzheimer's disease (Davis, 1989: Lee, 2003). They conclude that there are some people with Alzheimer's disease who develop early insight which continues throughout their illness.

This is reflected in the present study as the participants' awareness evoked a need to manage their impairments in the workplace and develop strategies to compensate, such as the use of diaries, structured calendars and audio recorders. Unlike the participants in the study by Ohman et al. (2001) they found these strategies useful. However, they were time consuming and required meticulous organization and preparation for work tasks. Unfortunately, much of this planning and organising were done secretively in an attempt to conceal difficulties from their colleagues and managers and so these strategies were not used openly. These attempts at adaptation may have been more effective if they had been used openly and with the cooperation of their colleagues. However, the fact that this was not done could signal underlying reasons for their covert behaviour.

It is unclear why the self-awareness that something was wrong was kept hidden. It could be that the participants accommodated in order to allow for better understanding and insight at this early stage and to assess whether the problems abated with time. Equally, and concurrently, they may have feared stigmatization in the event that these changes were both pathological and long lasting.

Employees who develop an illness or disability while in employment are entitled to protection under the Equality Act (2010). This Act entitles them to 'reasonable adjustments' in the workplace. This could include a change of role, a reduction in hours and the provision of a support worker to assist them in their work. The definition of what might be 'reasonable' remains largely untested and elusive but it is clear that the law is intended to be facilitatory and not in any way punitive yet evidence in this study points to a mixed picture.

As far the data in the present study are concerned, there appears to be a clear difference in the experiences of the participants. In the case of the School Meals Assistant, colleagues were asked to assist her with certain activities and in the case of the Nursing Assistant, colleagues were asked to unofficially supervise his interactions with patients. These may have been considered as 'reasonable adjustments' but as these 'interventions' were not discussed openly with the participants, they were felt to be punitive and in the case of the Nursing Assistant, stressful to the point of making their performance worse. Given these effects, it is difficult to see how this type of action could be seen as facilitatory.

In the case of the HGV Driver, it would appear that no adjustments were offered whatsoever but instead he was allowed an extended period of sick leave followed by summary dismissal. 
The experiences of the Engineer and the Businessman were quite different: Despite very similar early awareness of their problems, the consequences for employment were less severe. Both described themselves as semi-retired and remained employed in a capacity which allowed for the use of their skills in contrast to the other participants. The specific reasons for this are unclear yet it could be surmised that their ability to maintain employment was a matter of the locus of control over their work. In the case of the Businessman, he was the owner of the business and in the case of the Engineer the relative rarity of his talent and the need for his employer to preserve them meant that accommodation created benefits on both sides of the employer-employee relationship.

Added to this, both had a degree of unique knowledge about their work: knowledge that could not easily be replaced and which was valued by the business and university in the case of the businessman and lecturer/engineer, respectively. In the case of the businessman, this related to his input on strategic decisions and in the case of the engineer, his international contacts. In both cases, each had a degree of control and/or choice about their work involvement.

On the other hand, the dismissal from employment of the Nursing Assistant, School Meals Assistant and the HGV Driver seems to show an 'all or nothing' approach from employers with little consideration given to the possible use of their remaining skills, both for the good of the individual and for the workplace. Again, the reasons for this are unclear yet delineation exists between higher level occupations exercising a greater locus of control in this present study. According to the The National Statistics Socioeconomic Classification (NS-SEC rebased on the SOC2010) (Office of National Statistics, 2010) in the 3-class version of the NS-SEC rebase, the Engineer and Businessman would be categorized in level 1 (Higher managerial, administrative and professional occupations) and the School Meals Assistant, HGV Driver and Nursing Assistant would be in class 3 (Routine and manual occupations).

More importantly, if the results of this limited study are reflective of a bigger picture, there is a clear gulf between the notional rights of workers in NS-SEC class 3 with a disability and the reality for this group in the workplace. Their loss of locus of control, possibly as a reflection of their employers' view of either their relative lack of economic worth or easy replacement, had additional burdens placed on this group.

Each felt a sense of being abandoned by the workplace as no one from work contacted them after they were dismissed or put on sickness leave. Furthermore, a refusal to let workers say goodbye to their colleagues accentuated this perceived lack of care and compassion which may have further led to feelings of resentment towards the workplace. This is in contrast to the experiences of the employees with dementia in the Swedish study (Ohman et al., 2001) who were better supported in work with the assistance of their private health insurance schemes.

In the UK setting, Brechin (2004) suggests that some people with a dementia who are dismissed from work and have not been offered 'reasonable adjustments' would be justified in bringing a case of wrongful dismissal against their employers. In this present study, the Nursing Assistant may have had grounds to do so. However, the likelihood of people with a dementia, especially those who are newly diagnosed, emotionally 
vulnerable and not a member of a Trade Union (as was the case for the study participants) bringing such a case is unlikely.

Despite their difficult experiences, four out of the five participants expressed an acceptance of the outcome of their employment situation and all five were determined to have a positive outlook for the future. This positive outlook could be influenced by a sense of relief at knowing what is wrong and being able to explain their difficulties to others and having the opportunity to engage in new activities, (Jha, Tabet, \& Orell, 2001: McErlean, 2002: McKillop, 2005: Vernooj-Dassen, 2006).

For the HGV Driver and the School Meals Assistant, it could also be that they had been away from work for so long that they had time to rationalize their situation. The participant that expressed the lowest level of satisfaction with the outcome of his employment situation was the Nursing Assistant. He had his employment terminated very quickly and did not have time to adjust to the changing situation. It is still to be seen whether his experiences in employment will have a lasting effect on his mood and the progression of his illness. Certainly, this type of experience is unlikely to be mood enhancing and would be an interesting area of future investigation.

\section{Summary and conclusions}

There is no doubt that with the rise in the age of retirement, the numbers of people developing a dementia while still in employment will also rise. Though this is a small sample and the interpretation of events is that of the participant, the findings of this study seem to show that support for workers who have a dementia and who are employed in lower ranked occupations is, at best, poor and at worst unlawful. Consultation appeared nonexistent and referral to statutory agencies or adherence to the Equality Act (2010) appears to bear no regard to the wishes of the worker.

This study highlights the need for staff working in services for people with dementia to have some knowledge of Employment Law and to build up relationships with useful agencies in the field of employment. One simple and effective way of doing this is through Trades Unions who would be able to give an expert view of the legislation and give insights into the particular working roles of individuals. Most importantly, they could encourage the employer to engage in a dialogue which takes into account the employees' wishes when considering future plans and utilization of residual skills in the workplace. However, union density is currently running at $25 \%$ of the UK workforce (Brownlie, 2011) which means that this solution is only partial.

It is clear that this is a growing and imminent problem augmented by the removal of the statutory retirement age in 2012 . Although this small study limits the extent to which the results can be applied to the general population, it is clear that further research is needed to gauge scale of the ostensible problem and to assess the experiences of a larger sample of people who have undergone similar (or different) scenarios as those described in this current study. Distinction should be made between the experiences of those from different occupational groups. Only then will it be possible to plan for the inevitable problems that face people who develop a dementia while still in employment. 


\section{Acknowledgements}

The authors would like to sincerely thank the participants who took part in the study and Sarah Shaw for her assistance in verifying the analysis of the data.

\section{Declaration of Conflicting Interests}

The author(s) declared no potential conflicts of interest with respect to the research, authorship, and/or publication of this article.

\section{Funding}

The author(s) disclosed receipt of the following financial support for the research, authorship, and/or publication of this article: This research was carried out as part of a Masters in Clinical Research course at the University of Manchester which was funded by a National Institute of Health Research grant.

\section{References}

Alzheimer's Society. (2010). Employment. UK: Alzheimer's Society.

Armstrong, M. (2003). The needs of people with young onset dementia and their carers. Nursing times, 18, 681-684.

Beattie, A. M., Daker-White, G., Gilliard, J., \& Means, R. (2002). Younger people in dementia care: A review of service needs, service provision and models of good practice. Aging and Mental health, 6(3), 205-212.

Brechin, D. (2004). Dementia in the workforce. Science and Public Affairs, 6-8.

Brownlie, N. (2011). Trade Union Membership 2011. Department for Business, Innovation and Skills, Retrieved from http://www.bis.gov.uk/assets/BISCore/employmentmatters/docs/T/12-p77-tradeunion-membership-2011.pdf

Davis, R. (1989). My journey into Alzheimer's disease. Carol Stream, IL: Tyndale House.

De Baggio, T. (2002). Losing my mind: An intimate look at life with Alzheimer's disease. New York, NY: Free Press.

Equality Act. (2010). H.M.S.O.

Harris, P. B., \& Keady, J. (2004). Living with early onset dementia: Exploring the experience and developing evidence based practice guidelines for practice. Alzheimer's Care Quarterly, 5(2), 111-122.

Jha, A., Tabet, N., \& Orrel, M. (2001). To tell or not to tell: A comparison of older patients reaction to their diagnosis of dementia or depression. International Journal of Geriatric Psychiatry, 16(9), 879- 885.

Lee, J. L. (2003). Just love me: My life turned upside down by Alzheimer's. West Lafayette, IN: Purdue University Press. 
Luscombe, G., Brodaty, H., \& Freeth, S. (1998). Younger people with dementias: diagnostic issues, effects on carers and use of services. International Journal of Geriatric Psychiatry, 13, 323-330.

McErlean, S. (2002). Younger people with dementia and their spouses - a qualitative study. Journal of Dementia Care, 10, 38.

McGowin, D. F. (1993). Living in the labyrinth: A personal journey through the maze of Alzheimer's disease. New York, NY: Dell Publishing.

McKillop, J. (2005). Turning the corner when there's someone there to help. Journal of Dementia Care, 13, 17-19.

Ohman, O., Nygard, L., \& Borell, L. (2001). The vocational situation in cases of memory deficits or young onset dementia. Scandinavian Journal of Caring Sciences, 15, 34-43.

Office of National Statistics. (2010). Standard occupational classifications. Retrieved from http:// www.ons.gov.uk/ons/guide-method/classifications/current-standardclassifications/soc2010/ soc2010-volume-3-ns-sec-rebased-on-soc2010-usermanual/index.html

Office of National Statistics. (2012) Pension Trends. Index HTML Office of National Statistics.

Roach P. \& Keady, J. (2008). Younger people with dementia: Time for fair play. British Journal of Nursing, 17, 690.

Smith, J. A., Flowers, P., \& Larkin, M. (2009) Interpretive Phenomenological Analysis: Theory Method and Research. London: Sage.

Tindall, L. \& Manthorpe, J. (1997). Early onset dementia: A case of ill timing? Journal of Mental Health, 6, 237-249.

Vernooj-Dassen, M., Derksen, E., Scheltens, P., \& Moniz-Cook, E. (2006). Receiving a diagnosis of dementia: The experience over time. Dementia, 5(3), 397-410.

\section{Author Biographies}

Ruth Chaplin is an Occupational Therapist. Ruth currently works in Older Adult Mental Health Services in Stockport where she is a member of the Young Onset Dementia Team. She recently completed a Masters in Clinical Research Course at Manchester University. Ruth has many years of experience in the field of dementia, particularly in services for people under 65 who develop a dementia.

Ian Davidson is a Senior Lecturer in Physiotherapy, Manchester Metropolitan University (previously Lecturer in Rehabilitation at the University of Manchester). Ian has been a clinical and academic physiotherapist for 28 years. His clinical are in musculo-skeletal and neurological disorders. His research interests centre on intervention studies assessing the effect on physiotherapy on stroke, Guillain-Barré syndrome and migraine headache. 